\title{
Partnership in Communities of Practice Towards Teachers' Professional Development
}

\author{
Adeola Folasade Akinyemi \\ Vuyisile Nkonki \\ Teaching and Learning Centre, \\ University of Fort Hare, \\ Alice, South Africa
}

DOI: https://doi.org/10.36941/ajis-2020-0109

\begin{abstract}
This study examined how partnership with international agencies, non-governmental organisations and experts from higher institutions of learning assist teachers' in communities of learning towards their professional development. Mixed methods and concurrent triangulation research designs were adopted for this study. Seventy-nine respondents which comprises of principals, teachers, head of departments, cluster leaders, subject advisers and education district officials were purposively selected. Semi-structured questionnaire which has both open- and closed-ended questions as well as semi-structured interview which has both structured and unstructured interviews were the research instruments used to elicit information from the respondents. Quantitative data were analysed descriptively while quantitative data were analysed thematically from emerging themes. Findings revealed that greater percentage of high schools that participated in the study do not engage in partnership with international agencies, non-governmental organizations and experts from higher institutions in their communities of practice. However, few schools indicated that they enjoyed partnership from these organizations which had helped their teachers towards their professional development. Based on these findings, this study recommends that high school should try to engage in partnership programs especially with universities that are near to their school location to organise trainings, workshops and seminars for their teachers to serve as support measures for their professional development.
\end{abstract}

Keywords: professional development, assistance, collaboration, skills, engagement, new methods

\section{Introduction}

Partnership in communities of practice is crucial for the professional development of teachers. There exist strong and productive partnerships between schools and groups and organizations. According to Moore et al. (2019), over the years, many schools have engaged with a range of partners which include higher education institutions governing bodies, local community leaders, and non-governmental organisations (NGOs). These partnership programs helped to strengthen communities of practice which often kick start initial teacher's development and ensure on-the-job training for teacher on continuous and ongoing basis. Through these partnerships, teachers received professional help and advice from experts from various fields and areas of specializations.

Partnership is one of the processes established by communities of practice to enhance continuing professional teachers' development. For teachers to professionally develop in communities of practice, 
there is need for partnership (Lassonde \& Israel, 2010; Marquis et al, 2019). According to Lassonde and Israel (2010), partnerships in communities of practice are two types: school-based groups and schooluniversity groups. The essence of partnerships in communities of practice is to enable teachers to relate and learn together from other teachers and experts from higher institutions. This implies that for effective learning to take place in communities of practice, teachers need to relate with teachers from different schools and experts from higher institutions of learning. This will enable them to share ideas and even learn new methods and skills.

School-based groups are form of partnership in communities of practice that give support from teachers and school administrators or management at the local or district or state levels (Lassonde \& Israel, 2010; Chowdbury, 2018). These groups may include teachers from across districts or clusters with close proximity. Most of them may even know each other face to face before the collaboration and partnership program in communities of practice begin and most times this foster and accelerate development. School-university groups are a form of partnership and collaboration between schools and universities. This form of partnership is an alliance formed among the high school management or staff and the lecturers or professors from universities mainly for the purpose of professional development (Lassonde \& Israel, 2010).

In addition, the kind of partnership that exist between universities and high schools is very imperative and assist in their professional development in many ways. In a survey carried out by Lassonde and Israel (2010) on teacher research collaborations, they state that school teachers who completed their survey pointed out that they looked at their university partners to meet a variety of needs which include:

- Framing the study;

- Moving through the research process;

- Suggesting relevant readings and resources;

- Providing a sounding board to process and try out ideas;

- Helping to collect data during the school day;

- Advising how to sort, code and analyze data; and

- Assisting with writing up, disseminating and even publishing and presenting results.

On the other hand, Lassonde and Israel (2010) argue that the universities professors however state that they keenly engage in teacher research collaboration because it allows them to:

- Observe and become involved in teaching across grade levels;

- Stay abreast of current issues, methods and strategies in education;

- Engage in and learn from conversations with student, classroom teachers and administrators;

- See policies in action;

- Learn what equipment and materials are being used in the field; and

- Make contacts to aid the college student teaching needs.

This implies that partnership between schools and higher institutions of learning is a two-way learning. Teachers from the high schools learn from higher institution of learning lecturers as they are perceived to be experts and more skilful by the high school teachers. Lecturers from higher institution also see their involvement in teacher research collaboration as a learning process and also a means to be conversant with the education polices. Meacham, Castor and Felten (2013) state that the main goal of partnership in communities of practice is to provide professional development for teachers. Thus, there is a need for active engagement in diverse partnership programs with international agencies, NGOs and universities by teachers to learn and improve their skills which will help them to develop professionally.

In their study conducted in the United States of America (USA), McGraw et al. (2003) found that in the lesson study groups, the groups engaged in partnership with university mathematicians and educators for the purpose of professional development of the teachers in the groups. The groups consisted of middle and high school mathematics teachers, university mathematicians, university mathematics educators and pre-service secondary mathematics teachers. The programme was also 
partnered and funded by a technology foundation.

Partnership as one of the processes established by communities of practice to enhance continuing professional teachers' development is imperative as a way of engaging NGOs, experts from higher institutions and other stakeholders to get professional assistance, support and advice from different disciplines which will assist teachers in their professional development. Therefore, this study seeks to investigate how partnership in communities of practice help towards teachers' professional development.

\subsection{Objectives}

The main objective of this paper was to examine how partnership in communities of practice facilitate continuing professional teachers' development in high school in the Fort Beaufort Education District in Eastern Cape Province in South Africa. The paper also seeks to:

- find out if there is partnership with international agencies, NGOs or experts from higher institutions

- $\quad$ establish any financial assistance received by teachers from international agencies, private organizations or NGOs.

\section{Research Methodology}

Mixed methods approach were employed for this paper with the use of concurrent triangulation design in the collection of data. These methods were chosen because it helped to get expedient and in-depth information from the respondents about their view and opinions on partnership in communities of practice towards teachers' development in high schools (Creswell 2014). In this study, semi-structured questionnaires which have both open-ended and closed-ended questions as well as semi-structured interview which has both structured and unstructured interviews were used to solicit views and get information from the respondents. Some documents on communities of practices were also reviewed at the sampled schools and department of education.

Ten high schools were purposively selected from Fort Beaufort Education District because the chosen schools have engaged in communities of practice in their schools'. A total number of seventynine respondents were selected for this study. Sixty-four questionnaires were administered to the principals and teachers in the chosen schools while interviews were conducted for fifteen respondents include three teachers, three principals, three heads of departments, three cluster leaders, two subject advisors and one education district official were purposively chosen because of their in-depth knowledge about the phenomenon under study (Creswell 2014). Permission to collect data was obtained from the provincial department of education as well as from school principal of each selected high schools. Ethical principles were put into consideration in this study by giving consent form to all respondents to sign to indicate their voluntary participation, pseudo names were used for all respondents to protect their identity, thus all respondents remained anonymous (Oliver, 2010; De Vos etal, 2013).

Quantitative data were analysed using descriptive statistics in form of frequency counts and percentages while qualitative data analysed thematically by identifying, analysing and reporting themes within data. Quantitative and qualitative data were merged together as the findings of the study to have an in-depth information on partnership in communities of practice towards teachers' professional development.

\section{Results}

Presented in this section is the results of the analysis implemented in the methodology to address the main objective of the study, which is to examine how partnerships in communities of practice facilitate continuing professional teachers' development. The findings presented here address the study sub- 
objectives that sought to explore the kind of partnership with international agencies, NGOs or experts from higher institutions and what sort of assistance teachers get through funds from international agencies, private organizations or NGOs. Pseudo names were used for teacher, principal cluster leader, head of department, subject adviser and education district official respondents in this paper as TE1$\mathrm{TE}_{3}, \mathrm{PR}_{1}-\mathrm{PR}_{3}, \mathrm{CLL1}-\mathrm{CLL}_{3}, \mathrm{HOD} 1-\mathrm{HOD}_{3}, \mathrm{SA}_{1}-\mathrm{SA}_{3}$ and EDO respectively.

\subsection{Partnership with international agencies, NGOs or experts from higher institutions}

This information is vital as this study wanted to investigate different partnerships programs or help teachers engaged in their respective schools' communities of practice either through international agencies or experts from higher institutions. The findings are shown in Table 1 below.

Table 1: Partnership with international agencies, NGOs or experts from higher institutions

\begin{tabular}{ccc}
\hline $\begin{array}{c}\text { Do you partner with international agencies, NGOs or } \\
\text { expert from higher educational institutions }\end{array}$ & Frequency & Percentage \\
\hline Yes & 10 & 15.62 \\
No & 54 & 84.38 \\
Total & 64 & 100.00 \\
\hline
\end{tabular}

Table 1 above reveals that majority of the respondents, 54 (84.38\%) said no when asked if their schools' communities of practice partnered with international agencies or experts from higher institutions while ten respondents (15.62\%) were affirmative to the same question, implying that their schools' communities of practice partner with international agencies and experts from higher institutions.

Interviews were held with teachers, heads of departments, cluster leaders, principals and district official in order to get an in-depth information on partnership program that exist between their schools' communities of practice and any of these organizations. Teachers interviewed were asked if their schools' partner with private organizations, international agencies, experts from higher institutions or Non-Governmental Organizations (NGOs) and they should briefly discuss the partnership their communities of practice have engaged with and the benefits. TE1, TE2 and TE3 interviewed said their schools did not engage in any partnership with any of these organizations. Some of their responses are below:

TE1 said:

No, we do not partner with any of them for now, but I would have loved we do so. I know if we do, there will be some guidance we will get from them since they have experiences and this will help us as teachers.

TE3 replied:

We do not engage in any partnership program with either international organizations or experts from higher institutions

In their responses on the same question, $\mathrm{HOD} 1, \mathrm{HOD}_{2}$ and $\mathrm{HOD}_{3}$ respectively said no they do not engage in any partnership with either international organizations, NGOs or experts form higher institutions in their schools' communities of practice. However, HOD later said yes somehow, they have enjoyed partnership from a university through the donations made to his school. His comment is below.

HOD3 pointed out:

No and that is what I would like to happen here in this school. But yes somehow, there was a group from UK through a university that donated some equipment like wheel barrows, gloves to us. But I would like us to partner with more organizations in future. 
PR1 and PR2 also said they did not engage in any partnership program with either of the organizations. The following are their comments.

PR1 revealed:

Absolutely no engagement with expert from higher institution, this is where we have not yet started to intensify efforts in this regard. We have not consulted private organizations yet.

PR2 said:

We do not partner with any of these for now but we hope so in very soon to enhance teachers' professional development.

However, $\mathrm{PR}_{3}$ response differs from PR1 and PR2 responses, though she also said that they do not really engage in partnership program with private organizations or experts from higher institutions but somehow, they get support from one NGO that has been supporting the school in the last five years ago.

$\mathrm{PR}_{3}$ remarked:

We do not really partner with private organizations, international agencies or experts from higher institutions. But there is one NGO that is supporting us a lot. There was this woman who usually come here between January and February every year. She visits all the high schools in this cluster and she comes to our school also. She is a private person from Europe, she comes here every year. She likes us a lot. She does pay for someone that is taking our students, the grade 12 students basic computer learning to have basic knowledge of computer so that when they go to tertiary institutions, they will have the knowledge of how to use it.

Also, cluster leaders interviewed were asked if high schools in their cluster partner with private organizations, international agencies, experts from higher institutions or Non-Governmental Organizations (NGOs) and they should briefly discuss the partnership your cluster communities of practice have engaged in and the benefits derived. All the cluster leaders interviewed also said they did not partner with any of the mentioned organizations. The following are some of their comments.

CLL2 responded:

We do not have partnership program with them, none for now I must confess. We are trying to see how to engage in that most especially with university lecturers that are within our clusters.

CLL3 said:

No, we have not partner with any, we hope to soon. We have started the networking to get partnerships from various organizations and I know very soon our efforts will yield positive results.

District officials were also asked if high schools in their education district partner with any organizations, international agencies, experts from higher institutions NGOs and they should briefly discuss the partnership their communities of practice have engaged with and the benefits.

SAl commented:

I will say no. We do not partner with expert from higher institutions or NGOs. But what I know, they got twinning. There is a program in the district that is called twinning where by high schools in my education district they have got a partnership program with international high schools from America. So, during school's holiday, teachers use to go to America then on the other year teachers from those America schools will visit schools here. Otherwise, we do not have partnership for this program.

SA2 disclosed: 
We do partner with them, there are NGOs that are willingly to make partnership with district and schools with the hope of improving the teachers of teachers and for better results. For instance, there was one partnership we had sometimes, they come up with their materials, facilitating workshop for our teachers in various subjects, supporting materials and do a follow up to see if teachers are implementing what they have been taught to the level of getting result and to check the effectiveness of the training they have received.

EDO affirmed:

Sometimes ago we had some stakeholders who partnered with the department to support teachers but not mainly for cluster meeting. But for now, we do not engage in any partnership for the purpose of cluster meeting for teachers with any of these organizations.

Though responses from both the respondents and participants showed that some still said they engaged in some sorts of partnership programs from NGOs but majority of the respondents and participants said they did not engage in any form of partnership with these agencies and organizations. Documents reviewed from the sampled schools and at the district office also showed that there was no partnership engagement with either international agencies, experts from higher institutions, NGOs or other stakeholders. Most of the schools sampled which practiced informal communities of practice only get assistance from neighboring schools in their clusters or from the department of education.

\subsection{Assistance through funds from international agencies, private organizations or NGOs}

The study sought further information on assistance rendered to communities of practice through funds received from international agencies, private organizations or NGOs. The findings are presented in Table 2 below.

Table 2: Assistance through funds from international agencies, private organizations or NGOs

\begin{tabular}{ccc}
\hline $\begin{array}{c}\text { Do international agencies, private organizations or non-governmental organisations } \\
\text { assist the learning activities in communities of practice through funds }\end{array}$ & Frequency & Percentage \\
\hline Yes & 6 & 9.38 \\
No & 58 & 90.62 \\
Total & 64 & 100,00 \\
\hline
\end{tabular}

Table 2 above shows that majority of the respondents, 58 (90.62\%) said no which means that international agencies, private organizations or NGOs do not assist the learning activities in communities of practice through funds in their school while six respondents (9.38\%) said yes, implying that their schools received assistance through funds from those organizations in learning activities implemented in their communities of practice.

Documents reviewed from sampled schools showed that most of the schools got financial assistance from the department of education while in some schools, some teachers have to take money from their own pockets for the purpose of learning activities in communities of practice whenever there is an urgent need. Documents reviewed from the district office also showed that the department of education has assisted so many schools through funds for the purpose of cluster meetings in terms of materials they provided for teachers in order to enhance their professional development.

\section{Discussion}

Partnerships in communities of practice is essential for teachers' professional development. Bolam et al. (2005) note that many schools have engaged with range of partners over the years and the partnership they engaged in includes higher education institutions governing bodies, local community 
leaders, non-governmental organisations (NGOs). The findings showed that majority of the respondents indicated that their schools do not partner with international agencies or expert from higher education institutions. Contrary to the finding of the current study, Lassonde and Isreal (2010) noted that partnerships are seen as one of the processes established by communities of practice to enhance continuing professional teachers' development. For teachers to be professionally developed in communities of practice, there is need for partnership (Lassonde \& Israel, 2010).

The findings from the current study also showed that few respondents indicated that their school partner with international agencies and experts from higher education institutions in order to get assistance form them in terms of their teachers' professional development. Further findings from this study complements the study conducted in the United States of America (USA) by McGraw et al., (2003) on lesson study groups, they found that the group engaged in partnership with university mathematicians and educators for the purpose of professional development of the teachers in the group. They further found that the group consist of middle and high school mathematics teaches, university mathematicians, university mathematics educators and pre-service secondary mathematics teachers. The program was also partnered and funded by a technology foundation.

Moreover, the findings of the study also aligns with the study conducted by Jita and Ndlalane (2009) in South Africa, in which it was found that high school partnership with an international agency provide science teachers who participated in the cluster activities the help to challenge and change their subject content knowledge, pedagogical content knowledge and classroom practices with a rich set of opportunities to learn and to develop professionally. Similar, the findings of the current study corroborates the findings of Jita and Mokhele (2014) in South Africa which reveal how teacher cluster which consist of primary and secondary teachers of science and mathematics, cluster leaders and subject advisors collaborate and partner with professors from two universities. This helped them to improve on their professional development through the partnership program they engaged in. It was found in their study that one of the professors was from a local university and the other from Japan. It was also established form the study that few of the sampled high schools partner with NGOs that are willing to make partnership with district and those high schools with the hope of improving teachers and for better results which is mainly to enhance CPTD

The findings of the current study further revealed that few of the respondents said international agencies, private organizations or non-governmental organizations assist the learning activities in communities of practice through funds which is one of the strategies established by communities of practice to enhance CPTD. The findings of the study aligns with a study by Engels (2001) who found that in Uganda, school and cluster based approach through partnership with USAID funded program was used to help teachers improve their practice and help facilitate teacher discussion groups in the cluster. Likewise, the finding of the current study complement study by conducted by LeCzel and Liman (2003) where they found that in Namibia, through a partnership program which is also funded by USAID, teachers were able to improve the quality of teaching and learning in the school clusters and the program also promote the effective use of the curriculum that emphasizes students' active learning and critical thinking.

Conversely, results from our analysis showed that majority of the respondents indicated that they do not get financial assistance from international agencies, private organizations or non-governmental organizations in learning activities in communities of practice that could assist the communities of practice members to procure some educational materials that will enhance their professional development.

Likewise, Engels (2001) found that in Uganda, a school and cluster-based approach through partnership with the USAID-funded programme was used to help teachers improve their practice and help facilitate teacher discussion groups in the cluster. Similarly, LeCzel and Liman, (2003) reveal that in Namibia, through a partnership program also funded by the USAID, teachers were able to improve the quality of teaching and learning in the school clusters, and the programme also promoted the effective use of the curriculum that emphasizes students' active learning and critical thinking.

In their study in South Africa, Jita and Ndlalane (2009) found how partnership with an 
international agency provides participating science teachers in the cluster the help to challenge and change their subject content knowledge, pedagogical content knowledge and classroom practices with a rich set of opportunities to learn and to develop professionally. Similar studies by Jita and Mokhele (2014) also in South Africa reveal how in the teacher clusters, which consist of primary and secondary teachers of science and mathematics, cluster leaders and subject advisors collaborate and partner with professors from two universities. One of the professors was from a local university and the other from Japan. This partnership was seen to foster collaboration and professional development of teachers. Through the partnership in the cluster, teachers were able to develop and enhance their content knowledge and pedagogical content knowledge. It was also seen from the cluster that teachers had instructional guidance and teacher leadership. The cluster leaders were able to direct, coordinate, observe and even act as the facilitators (Ono \& Ferreira, 2010).

\section{Conclusion}

In conclusion, it is evident that despite the fact that majority of the schools that participated in this study do not enjoy partnership from international organisations, experts from higher institutions and NGOs, and only few high schools that engaged in various partnership derived some benefits. The partnership they enjoyed in form of assistance they got through workshops, educational materials has helped teachers towards their professional development.

\section{Recommendations}

Accordingly, partnerships and support from international organizations, NGOs and experts from higher institutions may enhance professional development in communities of practice. Thus, it is essential to solicit for this by school heads, department of education and other concerned stakeholders. The current study indicates that in terms of partnership, majority of the high schools do not get assistance from international organisation and non-governmental organisations. There is need for publicity and awareness by communities of practice key role players and stakeholders to solicit for partnership from relevant bodies to assist them in terms of their professional development. More so, school heads must explore partnership with experts from university or higher institutions most especially, those ones within their proximity for training of teachers, workshops and seminars.

\section{References}

Bolam, R., McMahon, A., Stoll, L., Thomas, S., Wallace, M., Greenwood, A., \& Smith, M. (2005). Creating and sustaining effective professional learning communities. London: Department for Education and Skills.

Chowdhury, R. (2018). Collaborative Partnerships Within Communities of Practice: The Need for School-Based Action Research in Bangladesh. In Engaging in Educational Research (pp. 159-178). Springer, Singapore.

Creswell, J. W. (2014). Research Design. Qualitative and Quantitative and Mixed Approaches (4 ${ }^{\text {th }}$ ed.). Thousand Oaks, CA: Sage.

De Vos, A. S., Strydom, H., Fouche, C. B., \& Delport, C. S. (2013). Research at grassroots: For the social sciences and human services professions. Pretoria, South Africa: Van Schaik Publishers.

Engels, J. (2001). Making classrooms talk: Uganda sustains its teacher improvement and support system. Washington, DC: Academy for Educational Development.

Jita, L. C., \& Mokhele, M. L. (2014). When teacher clusters work: selected experiences of South African teachers with the cluster approach to professional development. South African Journal of Education, 34(2), 1-15.

Jita, L. C., \& Ndlalane, T. C. (2009). Teacher clusters in South Africa: Opportunities and constraints for teacher development and change. Perspective in Education, 27(1), 58-68.

Lassonde, C., \& Israel, S. (2010). Teacher collaboration for professional learning facilitating study, research and inquiry communities. San Francisco, CA: Wiley \& Son Inc.

LeCzel, D. K., \& Liman, M. (2003). School self-assessment in Namibia: An adaptation of critical inquiry. Paper presented at CIES conference. New Orleans, LA. 
Marquis, E., Guitman, R., Black, C., Healey, M., Matthews, K. E., \& Dvorakova, L. S. (2019). Growing partnership communities: What experiences of an international institute suggest about developing student-staff partnership in higher education. Innovations in Education and Teaching International, 56(2), 184-194.

McGraw, R., Arbaugh, F., Lynch, K., \& Brown, C. (2003). Mathematics Teacher Professional Development as the Development of Communities of Practice. International Group for the Psychology of Mathematics Education, Paper presented at the 27th International Group for the Psychology of Mathematics Education Conference Held Jointly with the 25th PME NA Conference, (pp. 269-276). Honolulu, HI.

Meacham, M., Castor, M., \& Felten, P. (2013). Partners as newcomers: Mixed-role partnerships as communities of practice. Teaching and Learning Together in Higher Education, 1(10), 5.

Moore, M., O’Leary, P., Sinnott, D., \& O'Connor, J. R. (2019). Extending communities of practice: a partnership model for sustainable schools. Environment, Development and Sustainability, 21(4), 1745-1762.

Oliver, P. (2010). The student's guide to research ethics. McGraw-Hill Education (UK).

Ono, Y., \& Ferreira, J. (2010). A case study of continuing professional development through lesson study in South Africa. South African Journal of Education, 30, 59-74. 